Research Article

\title{
Collapse Mechanism and Full-Range Analysis of Overturning Failure of Continuous Girder Bridges
}

\author{
Taiyu Song $\mathbb{D}^{1,2}$ Qinger Deng, ${ }^{1}$ and Guoping $\mathrm{Li}^{2}$ \\ ${ }^{1}$ Tongji Architectural Design (Group) Co. Ltd., Shanghai 200092, China \\ ${ }^{2}$ Department of Civil Engineering, Tongji University, Shanghai 200092, China \\ Correspondence should be addressed to Taiyu Song; 1510008@tongji.edu.cn
}

Received 25 February 2021; Revised 27 April 2021; Accepted 11 May 2021; Published 25 May 2021

Academic Editor: Youyou Zhang

Copyright (c) 2021 Taiyu Song et al. This is an open access article distributed under the Creative Commons Attribution License, which permits unrestricted use, distribution, and reproduction in any medium, provided the original work is properly cited.

In recent years, failings of girders due to overturning in continuous girder bridges have repeatedly occurred in China. To investigate the overturning collapse mechanism and also to evaluate the rationality of anti-overturning design method using beam element models that are commonly adopted in practical design, detailed 3D finite solid element models of a typical single-column pier three-span continuous box girder bridge were built and a full-range numerical analysis of the models was conducted. The solid models included the prestressing effect and diaphragms. Both boundary and geometric nonlinearities were taken into consideration. Bearings were modeled considering the actual construction and dimensions of pot rubber bearings, the material characteristics and boundary conditions of rubber pads, and the contact properties between each part of the bearings. The analysis results revealed that the behavior of the bridge approached the nonlinear state at the onset of first bearing disengagement; the rotation (overturning) mechanism of the girder was gradually transitioned from deformable-body rotation to rigid-body rotation; all the end and middle bearings had been disengaged totally or locally at ultimate overturning failure. The analysis results also showed that bearing disengagements would lead to the ineffectiveness of the constraint in the transverse direction, which significantly reduced the overturning ultimate load and structural ductility before the final collapse. Prior to the first bearing disengagement, the vertical reactions calculated from the beam model were in good agreement with those from the solid model, while the transverse reactions were not. The behaviors were inaccurate after bearing disengagement in the beam models in which the movement of the rotation axis and transition of rotation mechanism failed to be realized. Reliable transverse stoppers and tensile anchors at bearing sections were recommended to efficiently improve anti-overturning stability and ductility in practical design.

\section{Introduction}

Multi-span continuous girder bridges have been widely adopted in urban viaducts and overpasses around the world for economic and feasible reasons. Since 2007, failures of urban viaducts and overpasses have occurred repeatedly in China due to the lateral overturning and falling down of the girders $[1,2]$. On October 10, 2019, the collapse of a viaduct bridge in Wuxi of Jiangsu Province revived widespread social attention, and the relevant survey showed that the prestressed concrete box girder of the incident bridge overturned and fell down under the torsion induced by the eccentric loads of overloaded vehicles. As these types of overturning failures hardly give any obvious indications, they lead to unacceptable casualties and huge losses once the collapse occurs. Therefore, there is a special need for an indepth discussion on this topic so as to prevent these types of failures.

In China, the bridges involved in overturning incidents have three major common characteristics $[3,4]$ : (1) continuous girder bridges, most of which have a single support at each middle pier (single support bridges for short and thereafter); (2) the superstructure is an integral box-section girder; (3) straight girders or curved girders with a large curvature radius. Studies on the analysis and design methods of anti-overturning of continuous girder bridges, especially for single-support bridges, have been conducted by many researchers [3-21]. Based on these researches, the Chinese 
bridge code (MTPRC 2012) [5] added the provisions for anti-overturning requirements of box girder bridges to the previous version (MTPRC 2004) [6]. Furthermore, the latest version (MTPRC 2018) [1] added two critical states defined in the entire overturning process of single-support bridges, and the previous anti-overturning requirements were revised. Previous researches related to overturning failures of single-support bridges still have some disagreements and insufficiencies, which are concluded in the following three aspects: (1) collapse mechanism of overturning failure of continuous girder bridges under eccentric loads; (2) meticulous simulations with realistic mechanical behaviors of each part of rubber bearings and the interaction between each part; (3) full-range nonlinear analysis of the entire overturning process. In addition, previous investigations are mainly conducted based on the outdated code (MTPRC 2012) [3, 7-10], while the research regarding the latest version (MTPRC 2018) is rare [12-14]. As a result, this study aims to address in-depth the above three critical issues in overturning failures and evaluating the rationality of the anti-overturning design method adopted in the current code (MTPRC 2018).

\section{Literature Review and Critical Issues}

2.1. Chinese Code. To illustrate the anti-overturning design method in the Chinese codes, a typical single support, threespan continuous girder bridge example with symmetrical structural configuration and loading scheme is shown in Figure 1 . The vertical reactions at each bearing under dead load $(G), a_{i}, b_{i}$, and $c_{i}(i=1,2)$, and the vertical reactions under live load $(P), A_{i}, B_{i}$, and $C_{i}(i=1,2)$, are calculated using beam models in practical design. According to the previous code (MTPRC 2012) [5], the anti-overturning stability factor $\lambda 1$, which is required to be over 2.5 , is defined as follows:

$$
\lambda_{1}=\frac{\sum S_{G, i}}{\sum S_{P, i}}
$$

, where $\sum S_{G, i}$ is the stabilizing effect, defined as the moment induced by the reactions under the $G$ regarding a hypothetical overturning axis (i.e., Line $\mathrm{C}$ in Figure 1), and $\sum S_{P, i}$ is the overturning effect, defined as the moment induced by the $P$ regarding the same overturning line. Accordingly, as for the example illustrated in Figure 1, and considering the equilibrium condition under the $P, \lambda_{1}$ is

$$
\lambda_{1}=\frac{2\left(a_{1} l_{a c}+b_{1} l_{b c}\right)}{P l_{P c}}=\frac{a_{1} l_{a c}+b_{1} l_{b c}}{A_{1} l_{a c}-B_{1} l_{b c}} .
$$

In the latest code (MTPRC 2018) [1], the anti-overturning stability factor $\lambda_{2}$ has the same expression as equation (1) while the corresponding $\sum S_{G, i}$ and $\sum S_{P, i}$ are redefined as the moments induced by the reactions only at the bearings on the noneccentric loaded side regarding the bearings on the other side under the $G$ and $P$, respectively. Using the same example in Figure 1 and the equilibrium condition under the $P, \lambda_{2}$ is

$$
\lambda_{2}=\frac{\sum\left(a_{i} l_{a c}\right)}{\sum\left(A_{i} l_{a c}\right)}=\frac{a_{1} l_{a c}}{A_{1} l_{a c}}=\frac{a_{1} l_{a b}}{A_{1} l_{a b}}=\frac{2 a_{1} l_{a b}}{P l_{P b}-2 C_{1} l_{b c}} .
$$

From the comparison between equations (2) and (3), it could be directly concluded that (1) $\lambda_{1}$ is always larger than $\lambda_{2}$, indicating that the MTPRC (2018) produces more conservative results compared with the MTPRC (2012); (2) let the hypothetical overturning axis in the MTPRC (2012) be transformed from Line C to Line B (Figure 1), $\lambda_{1}$ will be just equal to $\lambda_{2}$. These two conclusions further illustrate that, although the MTPRC (2018) no longer uses the concept of overturning axes adopted in the MTPRC (2012), the MTPRC (2018) can be computationally regarded that the overturning axis is the center axis of a girder (Line B in Figure 1); furthermore, as the overturning axis is set farther from the center axis and closer toward the eccentric loaded side, the calculated anti-overturning ability of girder bridges will become greater.

2.2. Critical Issues. In the researches of collapse mechanism and full-range analysis of overturning failures of continuous girder bridges, the four critical issues are as follows:

(1) The security and rationality of the anti-overturning design method in the current codes

(2) The actual mechanism of overturning failures, including the definition of an overturning failure, the position of overturning axis at failure, and the relationship between bearing disengagements and overturning failures

(3) The influence of the parameters, such as mechanical behaviors of rubber bearings, contact nonlinearity of bearings, transverse stoppers, diaphragms, etc., on the analysis of overturning failures

(4) The difference of overturning failures between straight and curved continuous girder bridges, in other words, the effect of the horizontal curvature of girders

There are some common understandings as well as disagreements regarding each abovementioned issue:

Issue 1: Based on actual overturning incidents, Zhuang [3], Li et al. [7], Peng et al. [8], Xiong et al. [9, 10], and Chen et al. [11] verified the anti-overturning design method in the MTPRC (2012) and accordingly obtained a common conclusion that the method in the previous code produced obviously nonconservative results due to its rigid-body rotation mechanism, by which even under the incident vehicle loads, the $\lambda_{1}$ is over 2.5. Researches based on the MTPRC (2018) are rare and have not yet formed a unified conclusion. Peng $[12,13]$ reported that the method in the MTPRC $(2018)$ was over-conservative because it was established based on a deformable-body rotation mechanism which ignored the positive effects of self-weight and rigid-body rotation [13]. 


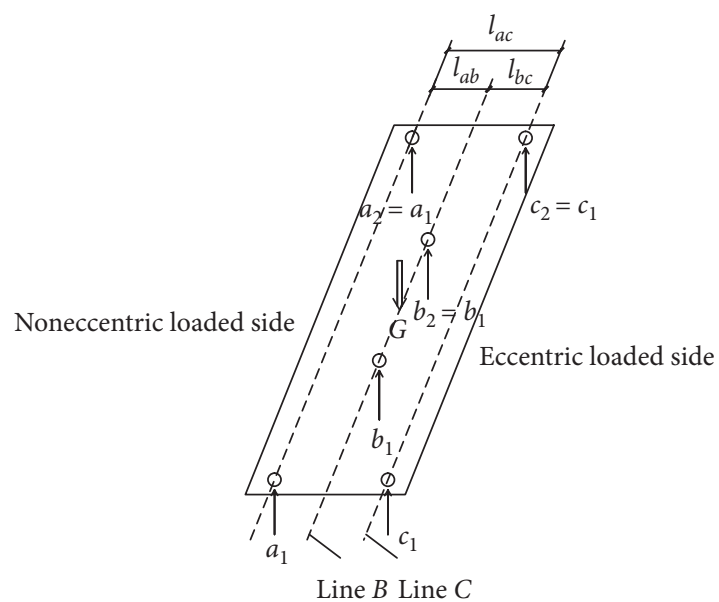

(a)

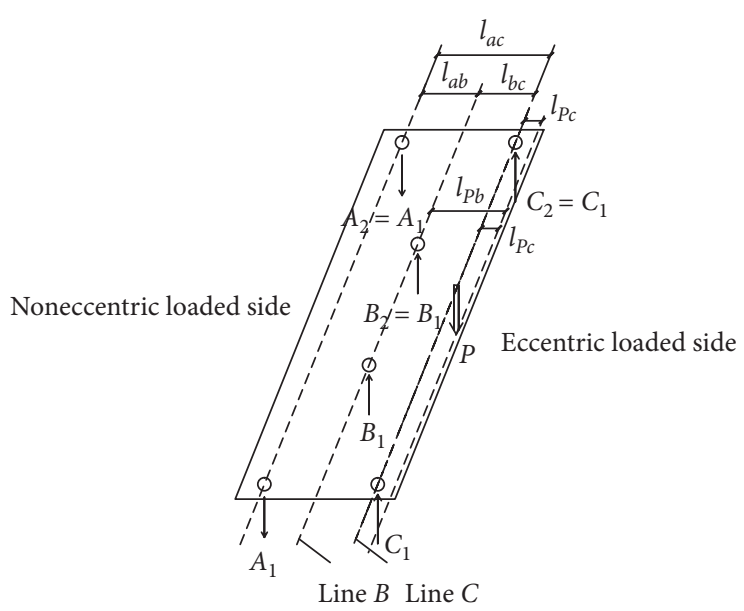

(b)

Figure 1: Vertical reactions in a single support bridge with symmetrical structural configuration and loading scheme. (a) Reactions under dead load $(G)$. (b) Reactions under live load $(P)$.

Issue 2: There is no precise definition of an ultimate overturning failure in worldwide codes [3]. Li et al. [7] concluded that rigid-body rotation and the ineffectiveness of transverse constraint due to excessive rotations were two overturning failure modes. Twist angles of all bearings were suggested to be less than $0.02 \mathrm{rad}$ to prevent the latter failure mode. Peng et al. $[12,13]$ reported that the mechanism of overturning failure was a combination of rigid-body large rotation and deformable-body small rotation. Based on deformable-body rotation mechanism [1], Peng et al. $[8,13,16]$ put forward different positions of overturning axis to consider the movement of resultant reactions at middle bearings during overturning process. However, the calculation of the bearing reactions still did not take into account the movement of the overturning axis. Fang [4] supposed that overturning failures would never happen until bearing disengagements occur and thus the bearing disengagement was an "early warning" for overturning failures. At present, there is no exact relationship between bearing disengagements and overturning failures, which in fact relate to structural configuration, loading type, loading position, etc., but the first bearing disengagement is undoubtedly a critical state in anti-overturning design $[4,17]$.

Issue 3: The mechanical behaviors of rubber bearings and the interaction between bearings and girders are important for the determination of the equilibrium condition at the ultimate state of overturning failures [3]. However, there is few detailed, full-range nonlinear analysis of overturning failures so far. Zhang et al. [18] established a 3D beam finite element model of the Chu Hui Viaduct in which nonlinear spring elements were used to simulate different constraint conditions at bearings and transverse constraint constructions. Using ANSYS and ABAQUS software, Xiong et al. [9, 10], Peng et al. [15, 16], Shi et al. [19, 20], Liu et al. [21], and
Lee et al. [22] developed detailed solid or shell finite element models of incident bridges, such as the Yang Ming Tan Bridge in Harbin, the Chu Hui Viaduct in Zhejiang, etc. The most detailed model among those established by Xiong et al. [10] considered the rubber in bearings as a hyperelastic material while the constrained rubber pads in the model might have different mechanical behavior from that of the rubber in actual steel pot bearings.

Issue 4: According to the investigations based on the MTPRC (2018) [10, 14], as the horizontal curvature increased, the anti-overturning stability factor $\lambda_{2}$ of curved girders would decrease; however, some researchers reported the opposite conclusion [13]. At least, this represents that the anti-overturning design method in the MTPRC (2018) has different degrees of security for straight and curved girder bridges.

This study is performed to investigate the collapse mechanism of overturning failures in continuous girder bridges and a full-range numerical analysis of a typical single-support bridge is conducted. Based on the numerical results, the critical issues as summarized above are deeply discussed; both the security and rationality of the antioverturning design method used in the codes are investigated and the corresponding suggestions for the practical design are also proposed in this study.

\section{Numerical Analysis of Single-Support Bridge}

3.1. Analysis Bridge. Based on the common characteristics of the bridges involved in overturning incidents as described in the "Introduction" section, a typical single support, threespan continuous prestressed concrete straight box girder bridge was selected as the bridge for analysis in this study. The structural and mechanical behaviors of the superstructure and bearings of the analysis bridge were investigated for the entire overturning process in which self-weight, 


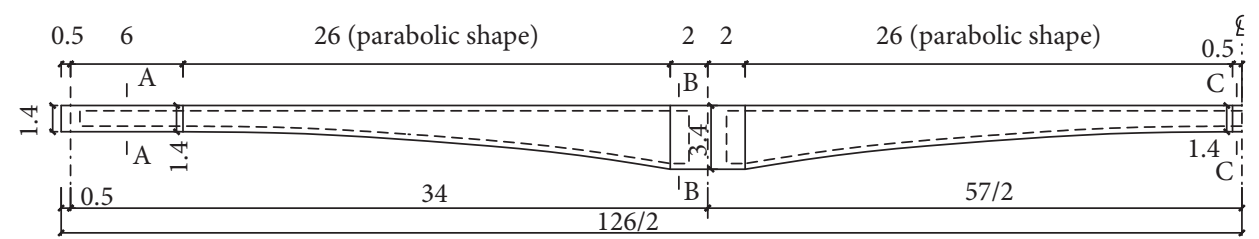

(a)

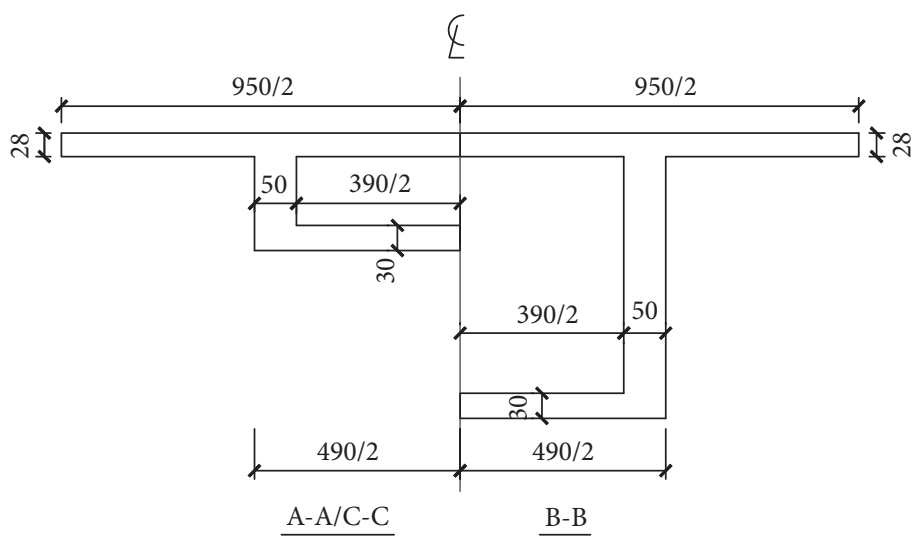

(b)

Figure 2: Layout of the analysis bridge. (a) Elevation (unit: m). (b) Typical cross section (unit: $\mathrm{cm}$ ).

prestressing, and eccentric vehicle load were loaded step by step.

The total length of the analysis bridge was $126 \mathrm{~m}$, with three spans of $34+57+34=125 \mathrm{~m}$, as shown in Figure 2(a). The supports at the end piers were fixed against rotation about the girder axis using two bearings (end bearings), each with a distance of $2.7 \mathrm{~m}$ symmetrically, whereas each support at the middle piers was arranged with one bearing in the center (middle bearing). Diaphragms were designed at each support with the same thickness of $1.0 \mathrm{~m}$. The cross section of the girder was a single-box, single-cell type with various heights between $1.4 \mathrm{~m}$ (midspan section of center span and end support section) and $3.4 \mathrm{~m}$ (middle support section) changed in a parabolic shape, as shown in Figure 2. The arrangement of prestressed tendons is shown in Figure 3. The prestressing effect must be considered in the model because the second effect of prestressing would influence the distribution of vertical reactions and accordingly the whole overturning process. To simplify, all the tendons were designed in the same elevation layout with a total effective prestress of $6.51 \times 10^{4} \mathrm{kN}$. The density $(\gamma)$ and elastic modulus $(E)$ for concrete in the model were $26 \mathrm{kN} / \mathrm{m}^{3}$ and $3.45 \times 10^{4} \mathrm{MPa}$, respectively. The $\gamma$ and $E$ for steel were $78.5 \mathrm{kN} / \mathrm{m}^{3}$ and $2.1 \times 10^{5} \mathrm{MPa}$, respectively. The $\gamma$ for rubber in bearings was $13 \mathrm{kN} / \mathrm{m}^{3}$.

The bearings applied to the analysis bridge included three types, as shown in Figure 4(a): GD, DX, and SX, representing the bearings restrained in both longitudinal and transverse directions, the bearings restrained only in the transverse direction, and the bearings with no restraint, respectively. It should be noted that the transverse constraints at the end supports were applied to the end bearings on the eccentric loaded side ( $S 1, S 1^{\prime}$ in Figure 4(a)). The bearings were pot rubber bearings which were commonly adopted in medium-span continuous girder bridges [23, 24]. According to the estimated vertical reactions, the types of the end and middle bearings were selected as GPZ2 and GPZ10 [25], respectively.

According to the weight of the heaviest incident vehicle $(163.6 \mathrm{t})$ in the Yang Ming Tan Bridge $[2,9]$, which had a very similar span arrangement as the analysis bridge, the eccentric vehicle load $P_{0}$ was approximately designed as $1700 \mathrm{kN}$ (Figure 4(b)). The $P_{0}$ was designed as one point load applied at the midspan of center span, for two reasons: (1) the midspan of the center span was very close to the lowest position of the reaction influence line for the end support sections, corresponding to the smallest load to disengage the bearings at the end supports; (2) the load applied to the symmetry plane of the analysis bridge could result in simultaneous disengagements of the end bearings on the noneccentric loaded side (S2, S2' in Figure 4(a)), corresponding to the most unfavorable condition for anti-overturning stability [1]. The transverse position of the $P_{0}$ was designed based on the condition that the vehicle wheels were as close as possible to one side barrier, corresponding to an eccentricity of $3.25 \mathrm{~m}$, as shown in Figure 4(b).

3.2. Finite Element Models. To conduct the full-range numerical analysis and verify the rationality of the antioverturning design method in practice, a detailed nonlinear $3 \mathrm{D}$ solid element model and an elastic 3D beam element model of the analysis bridge were built using ABAQUS/ Standard [26] and MIDAS CIVIL software, respectively.

3.2.1. The Detailed Nonlinear 3D Solid Element Model (Short as Solid Model and Thereafter). To save computational cost, half of the analysis bridge was established in the solid model 


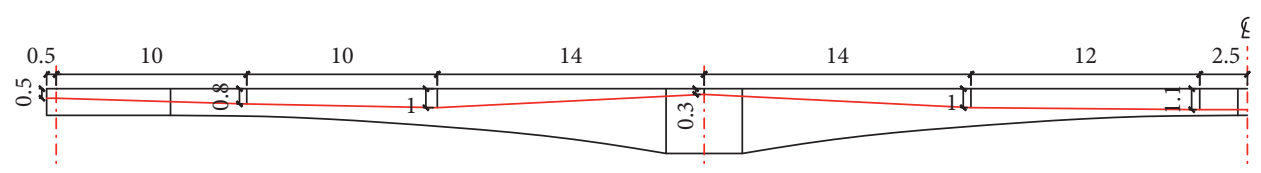

Figure 3: Elevation layout of prestressed tendons (unit: $\mathrm{m}$ ).

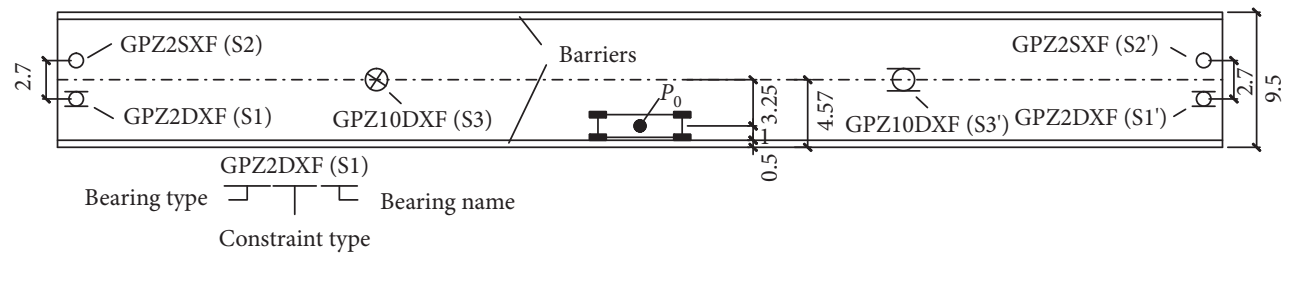

- Eccentric loading point

(a)

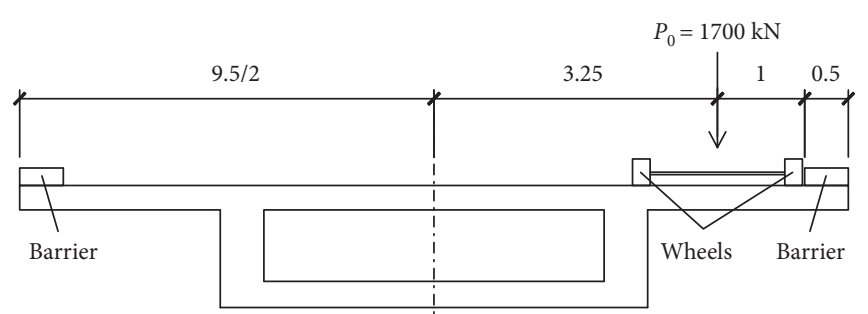

(b)

Figure 4: Layout of bearings and position of eccentric load $P_{0}$ (unit: m). (a) Plan. (b) Cross section.

based on its symmetry. Based on the on-site information about the overturning incidents $[3,9,16]$, the superstructures of the overturned bridges typically showed good integrity without damage during collapses, so the material nonlinearity of the superstructure in the model was not considered. The concrete box girder (including diaphragms) was modeled using linear, reduced integrated, and hex solid elements. The prestressed tendons were modeled using linear, 3D truss elements, degrees of freedom of which were automatically coupled with those of adjacent concrete elements. The loading procedures in the analysis are listed in Table 1 . The prestressing was applied to tendon elements by predefining the tendons with a specific negative temperature. Half of the multiples of the $P_{0}$ were applied incrementally until computational divergence due to excessive rotational deformations, which represented that the model reached the ultimate limit point. The eccentric vehicle load was set in an unchanged gravitational direction in the whole analysis. The model included the nonlinear effects of large deformations and displacements (geometric nonlinearity) in the analysis.

The accurate simulation of the boundary conditions of girder bridges is critical for overturning analysis [9]. In the solid model, the actual constructions of the pot rubber bearings were carefully modeled according to the pot bearing standard [25]. Both the material nonlinearity of rubber and the boundary nonlinearity of the bearings were taken into account in the model. As shown in Figure 5, the bottom surface of the bearings was fixed. The different contact interaction properties between each individual part of the pot bearings were modeled using the surface-tosurface method. For the normal behavior, the interaction between contact pairs used "hard" contact that when the contact pressure reached zero or negative, the contact pairs became separated. For the tangential behavior, the interaction between contact pairs used the finite sliding mode based on the Coulomb friction formulation. The friction coefficients $(\mu)$ for the surfaces of steel-to-steel, steel-torubber, and steel-to-PTFE were 0.2, 0.7, and 0.03, respectively [24]. The top steel plate and PTFE plate of the bearings were omitted in the model, and accordingly the middle steel plate was directly contacted with the bottom surface of the girder. The different types of the bearings (GD, DX, and SX) were simulated using the different friction coefficients and transverse stoppers. As shown in Figure 5, the rubber was surrounded by the steel basin and top steel plate, resulting in a triaxial constrained state in the pot bearings.

The basin, intermediate plate, and transverse stopper of the bearings were steel and modeled by solid elements. Rubber is a hyperelasticity material that can be hardly compressed and the corresponding Poisson ratio $(v)$ is close to 0.5 , and as a result, the rubber in the bearings was modeled using hybrid elements to avoid volumetric locking problem. The stress-strain relationship of the hyperelasticity material is described by strain energy functions. This model used the Mooney-Rvilinin model, which was one of linear strain energy functions and commonly used in practice [24]. The constitutive parameters in the Mooney-Rvilinin model 
TABLE 1: Loading procedures in the models.

\begin{tabular}{lccc}
\hline Model & Step 1 & Step 2 & Step 3 \\
\hline The solid model & Self-weight & Prestressing & Eccentric vehicle load $P / 2, P=P_{0}, 2 P_{0}, 3 P_{0}, \ldots$, applied incrementally until failure \\
The beam model & Self-weight & Prestressing & Eccentric vehicle load $P, P=P_{0}$, applied at one time \\
\hline
\end{tabular}

Note: The loads created in one step were propagated in the subsequent steps.

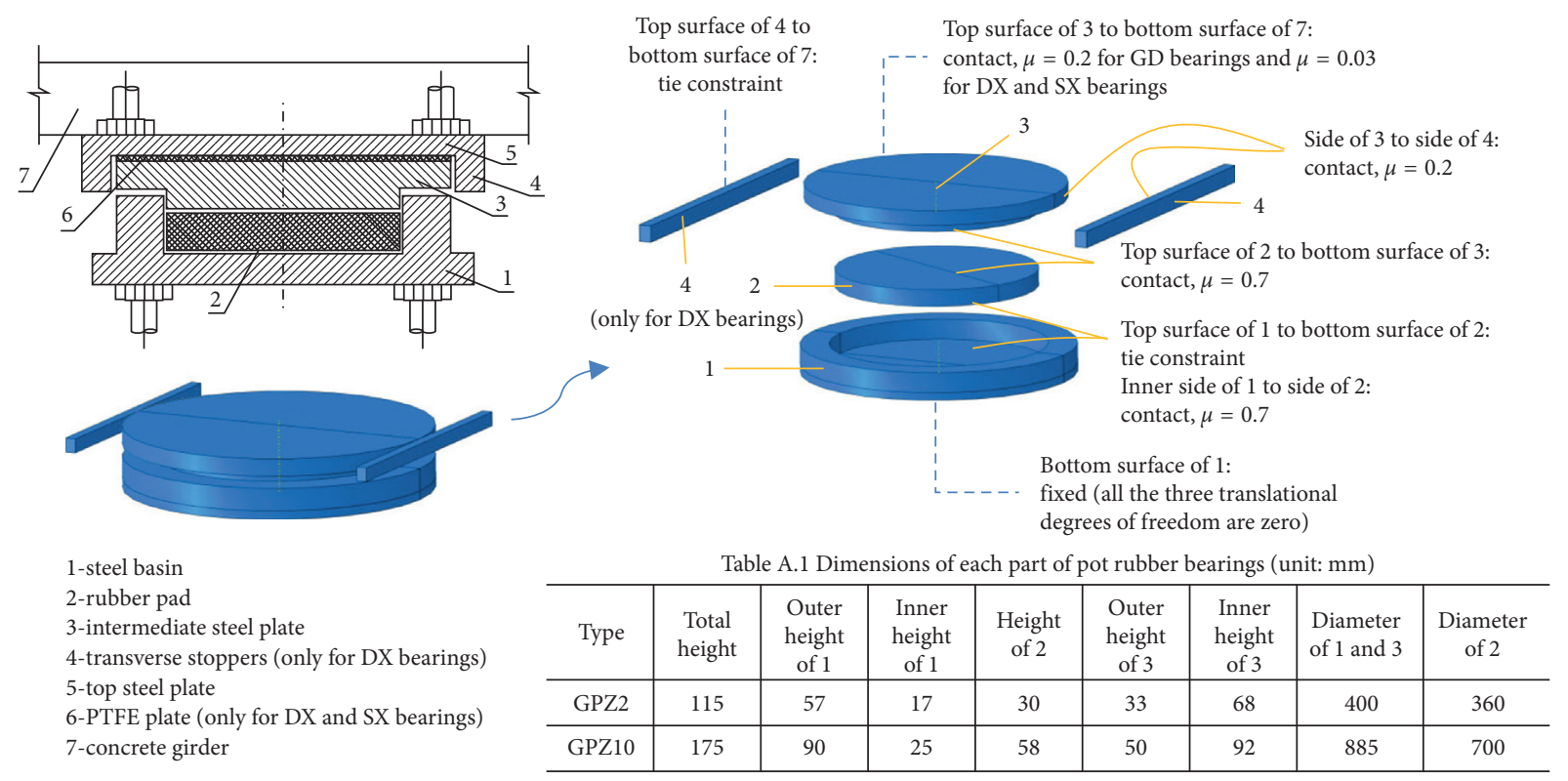

FIgURE 5: Constructions, dimensions, and contact parameters of the pot rubber bearings in the model.

mainly depend on the hardness of rubber, which were taken as $\quad C_{10}=0.4825 \mathrm{MPa}, \quad C_{01}=0.1206 \mathrm{MPa}, \quad$ and $D_{1}=10^{-3} \mathrm{MPa}^{-1}$, corresponding to the $v$ of 0.49975 . The total heights and diameters of the pot rubber bearings were determined based on bearing types (GPZ2 and GPZ10) [25]. The thickness of the rubber pad was taken as one twelfth of its diameter [23]. The dimensions of each part of the bearings were listed in Table A.1 in Figure 5.

The finite element mesh of the solid model is shown in Figure 6. The global size of the mesh of the girder was approximately $30 \mathrm{~cm}$ and the size of the mesh of the pot bearings was $2 \mathrm{~cm}$. The mesh of the bottom flange of the girder was locally refined for the region around the bearings, as shown in Figure 6. It is noted that, when the whole analysis bridge model was symmetrically reduced to half of the model, the middle bearing (S3 in Figure 4(a)) should be changed from GD type to DX type to remove the redundant constraint in the longitudinal direction, as shown in Figure 6.

3.2.2. The Elastic 3D Beam Element Model (Short as Beam Model and Thereafter). In practice, the most general method to estimate the structural behaviors of bridges is to perform a linear elastic analysis (overturning analysis included) using beam models. To verify the security and rationality of the anti-overturning design method based on beam models, a beam model of the same analysis bridge was established using MIDAS CIVIL, as shown in Figure 7.
The beam model was build based on the centroidal axes of the girder [2]. The supporting points were connected to the corresponding support sections using elastic links, as shown in Figure 7 . The stiffness of the elastic links was set as zero in the nonconstrained directions and set as a very large and unified value of $10^{6}(\mathrm{kN} / \mathrm{m})$ in the constrained directions. Taking into account the possible bearing disengagements, the bearings $\mathrm{S} 2$ and $\mathrm{S} 2{ }^{\prime}$, which were expected to be disengaged under the eccentric load, employed the compression-only bearings. The material and geometric nonlinearity were not considered in the beam model. The loading procedures in the analysis are listed in Table 1 . The eccentric vehicle load $\left(P=P_{0}\right)$ was applied one time in the beam model.

\subsection{Analysis Results}

3.3.1. The Axial Stiffness of the Pot Rubber Bearings. In engineering design, the axial (vertical) stiffness of each bearing is usually taken as a unified value for simplicity. However, the relative axial stiffness of bearings affects the distribution of reactions in a continuous girder bridge, and further affects bearing disengagements and overturning process of the bridge. To investigate the influence of this simplification, a test on the axial stiffness of bearings was conducted using the pot rubber bearing model established in the solid model.

Figure 8 shows the axial load-deformation curves of the end and middle bearings, respectively. The applied loads 


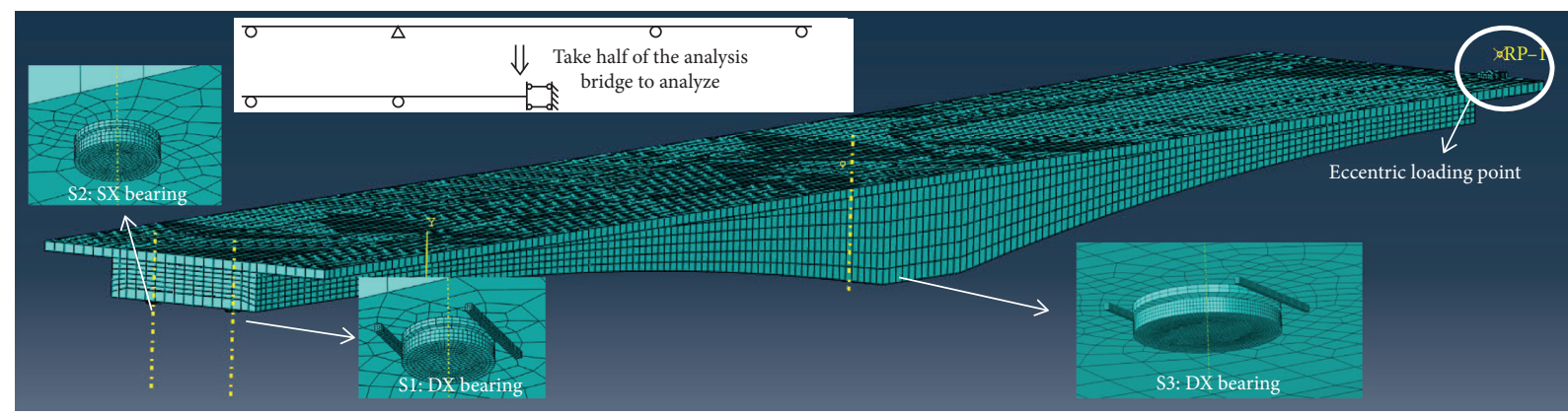

FIgURE 6: The solid model (half model) and mesh of the analysis bridge.

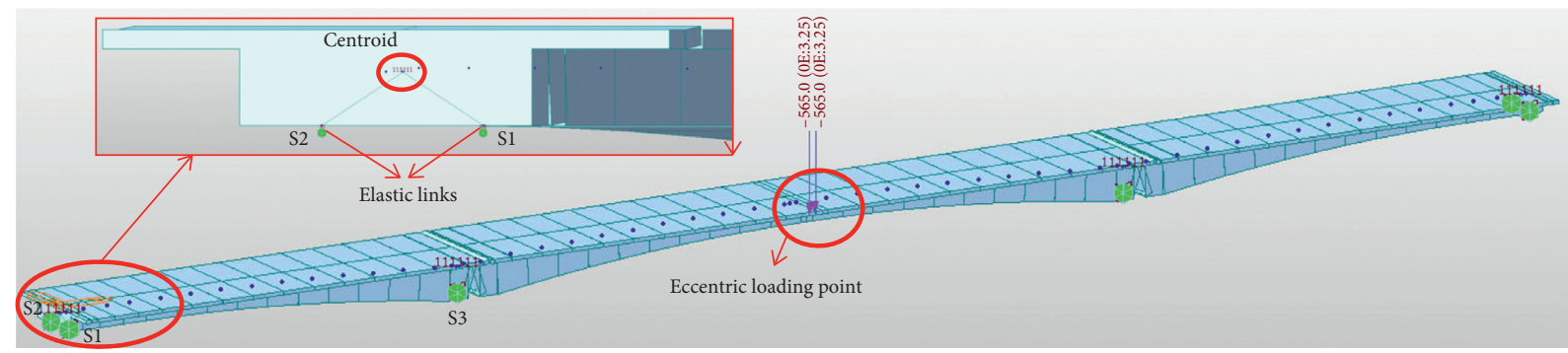

FIgURE 7: The beam model of the analysis bridge.

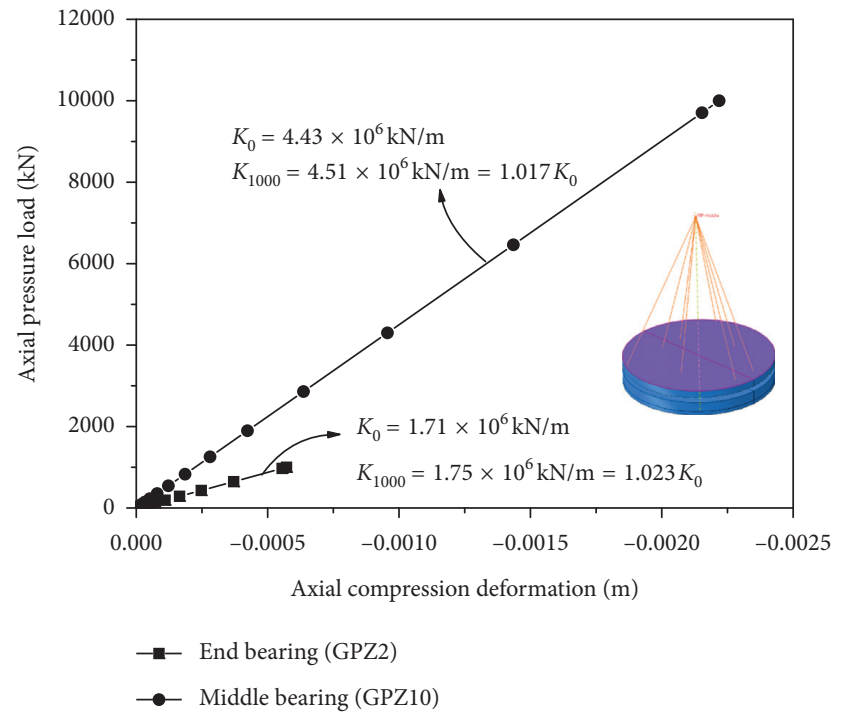

Figure 8: Axial load-deformation relationships of the pot rubber bearings.

were uniform pressures in the reasonable range of the reactions at the serviceability limit state. The initial axial stiffness $\left(K_{0}\right)$ of the end and middle bearings were $1.71 \times 10^{6} \mathrm{kN} / \mathrm{m}$ and $4.43 \times 10^{6} \mathrm{kN} / \mathrm{m}$, respectively, calculated based on the slope of the load-deformation curves. As the applied pressure increased, the stiffness of the bearings had a slight increase within $2 \%$, indicating that it is a reasonable simplification that the axial stiffness of bearings keeps constant at the serviceability limit state. According to the deformation of the rubber pad, the calculated initial elastic modules $(E)$ of the rubber were approximately $1250 \mathrm{MPa}$ and $1400 \mathrm{MPa}$ for the end and middle bearings, respectively, indicating that the rubber in the triaxial constrained state had a significantly larger elastic module compared with the nonconstrained rubber (typically around $0.1 \sim 8 \mathrm{MPa}$ ).

The vertical reactions in the first two steps from two beam models, in which the bearings used a uniformed stiffness $\left(1.0 \times 10^{6} \mathrm{kN} / \mathrm{m}\right)$ and the actual calculated stiffness $\left(1.71 \times 10^{6} \mathrm{kN} / \mathrm{m}\right.$ for the end bearings and $4.43 \times 10^{6} \mathrm{kN} / \mathrm{m}$ for the middle bearings), respectively, are listed in Table 2. Compared with the results from the beam model using the unified stiffness, there was a reaction transformation from the end bearings ( $\mathrm{S} 1$ and S2) to middle bearing (S3) for the beam model using the actual stiffness, because S3 in fact had a larger relative stiffness than those of S1 and S2. However, the magnitude of this transformation was slight that the relative differences were within $2 \%$; as a result, it is reasonable to set the axial stiffness of bearings as an appropriate unified value in practice.

3.3.2. Vertical Reactions of Bearings. The sum of vertical reactions from the solid model was slightly larger than those from the beam models (Table 2). This is because the beam models did not take into account the self-weight of the prestressing tendons. The variations in the vertical reactions of the bearings from the solid and beam models during the entire overturning process of the analysis bridge are shown in Figure 9. The abscissa in the plot was uniformly the applied eccentric vehicle load $P$. Before the first bearing disengagement, the reactions from the two models were very close. The end bearings on the unloaded side S2 in the solid 
TABLE 2: Vertical reactions in the first two steps from two beam models and the solid model (unit: $\mathrm{kN}$ ).

\begin{tabular}{|c|c|c|c|c|c|c|c|c|}
\hline \multirow{2}{*}{ Model } & \multicolumn{4}{|c|}{ Step 1} & \multicolumn{4}{|c|}{ Step 2} \\
\hline & S1 & $\mathrm{S} 2$ & S3 & Sum & S1 & S2 & S3 & Sum \\
\hline The beam model (using the unified stiffness) & 577 & 577 & 8437 & 9591 & 768 & 768 & 8055 & 9591 \\
\hline The beam model (using the actual stiffness) & 571 & 571 & 8449 & 9591 & 762 & 762 & 8067 & 9591 \\
\hline The solid model & 571 & 583 & 8464 & 9618 & 760 & 780 & 8078 & 9618 \\
\hline
\end{tabular}

Note: the positive vertical reactions were in the upward direction.

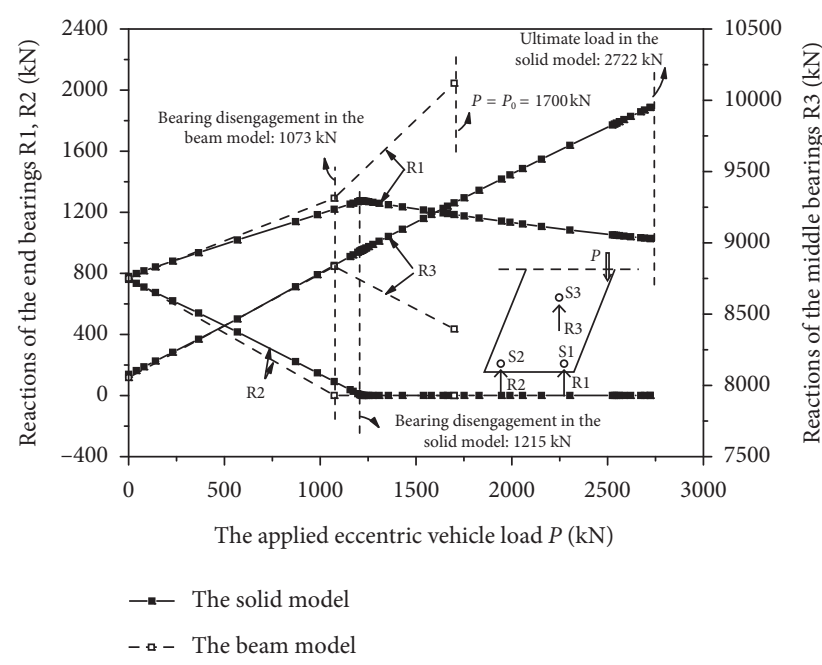

FIgURE 9: Applied load-vertical reactions relationships calculated from the beam and solid models.

and beam models were disengaged at loads of $1215 \mathrm{kN}$ and $1073 \mathrm{kN}$, respectively. The first disengagement load of the beam model was 0.88 times that of the solid model, indicating the beam model had a relatively conservative prediction regarding to the first disengagement compared with the solid model. As the disengagement of S2 corresponded to the $\lambda_{2}=1$ in the MTPRC (2018) [1], MTPRC (2018) was obviously conservative in this case, the magnitude of which would decrease in some degree for the cases that bridges were loaded unsymmetrically.

As shown in Figure 9, the vertical reactions calculated from the two models had significant differences after the disengagement of S2. For the beam model, the reaction of the other end bearing S1 (R1) increased faster than that before the disengagement and the reaction of the middle bearing S3 (R3) began to decrease; in contrast, R3 continued to increase and R1 began to decrease for the solid model. This indicates that the beam model failed to accurately predict the reactions after bearing disengagements because in the beam model, the end bearing section still rotated against the girder centroid axis after the disengagement of S2 (Figure 10(b)) and the sectional torsion (T) still increased linearly with the linearly increasing applied load. Consequently, as S2 had been disengaged, R2 could no longer decrease to be negative (S2 employed the compression-only type), and the increasing rate of $\mathrm{R} 1$ had to increase to keep the difference between R1 and R2 (corresponding to sectional torsion) increase in a constant rate. However, in fact, the torsion resistance system of the girder was qualitatively changed after the disengagement of S2 that the end bearing section came to be supported only by $\mathrm{S} 1$ and accordingly rotated against $\mathrm{S} 1$, as shown in Figure $10(\mathrm{c})$. This caused a dramatic drop in the resistance of torsional deformation in the end bearing section (the resistance was zero if the bearing size was ignored) and accordingly the torsion subjected to the end bearing section would significantly decrease. On the other hand, as the bending resistance system of the girder was not changed, the increasing rate of the total reactions of the end and middle bearing sections should keep unchanged. In the case of the disengagement of S2, to keep the increasing rate of the sum of $\mathrm{R} 1$ and $\mathrm{R} 2$ constant, the increasing rate of $\mathrm{R} 1$ inevitably decreased as the solid model predicted. It is concluded that the method using beam models incorporating compression-only type bearings [7, 13] cannot be applied to overturning analysis and anti-overturning design.

3.3.3. Torsional Deformations. The variations in twist angles at the end and middle bearing sections are shown in Figure 11 . Horizontal breaks from 0.04 to 0.25 in the plot were set to improve readability. Prior to the disengagement of S2, two supports at the end bearing sections constrained the torsional deformation of the girder and thus the girder had an insignificant torsional deformation. The twist angles at the onset of the first disengagement were $0.0019 \mathrm{rad}$ and $0.0018 \mathrm{rad}$ at the middle bearing section of the beam and solid models, respectively. The end bearings could hardly constrain the torsional deformation after the disengagement of S2 and thus the torsional deformations of the girder increased at a rapid rate then. When the applied load $P$ reached the ultimate load in the solid model, the twist angles at both the middle and end bearing sections were approximately $0.04 \mathrm{rad}$, exceeding the maximum required value of $0.02 \mathrm{rad}$ [25]. The comparison between the two models showed that the twist angles from the beam model were obviously larger than those from the solid model after the disengagement of S2. The twist angles at the bearing sections had been as large as $0.30 \mathrm{rad}$ at the load of the $P_{0}$, which was definitely not in accordance with the reality. This is also because the deformable-body rotation mechanism, as the torsional mechanism before bearing disengagements (Figure 10(a)), did not change after the bearing disengagement in the beam model. In the entire overturning process from the solid model, the twist angles at different sections of the girder tended to be consistent, indicating that the rotation (overturning) mechanism of the girder gradually transited from deformable-body rotation to rigid-body rotation; the rotation axis gradually transited from the 


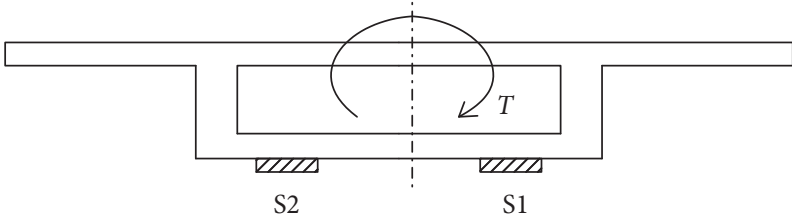

(a)

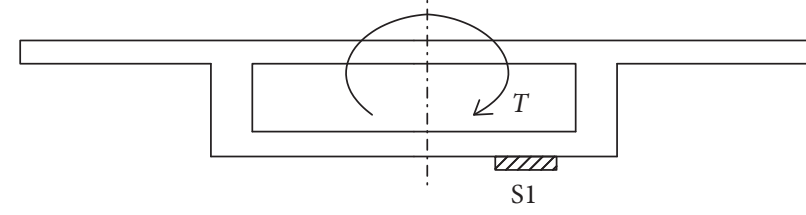

(b)

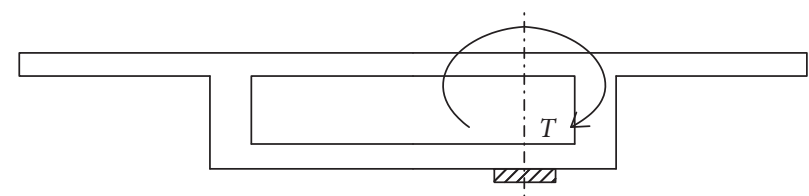

S1

(c)

FIGURE 10: Torsion resistance system at the end bearing section in the models. (a) Before the disengagement of S2: deformable-body rotation mechanism in the beam and solid models. (b) After the disengagement of S2: deformable-body rotation mechanism in the beam model. (c) After the disengagement of S2: rigid-body rotation mechanism in the solid model.

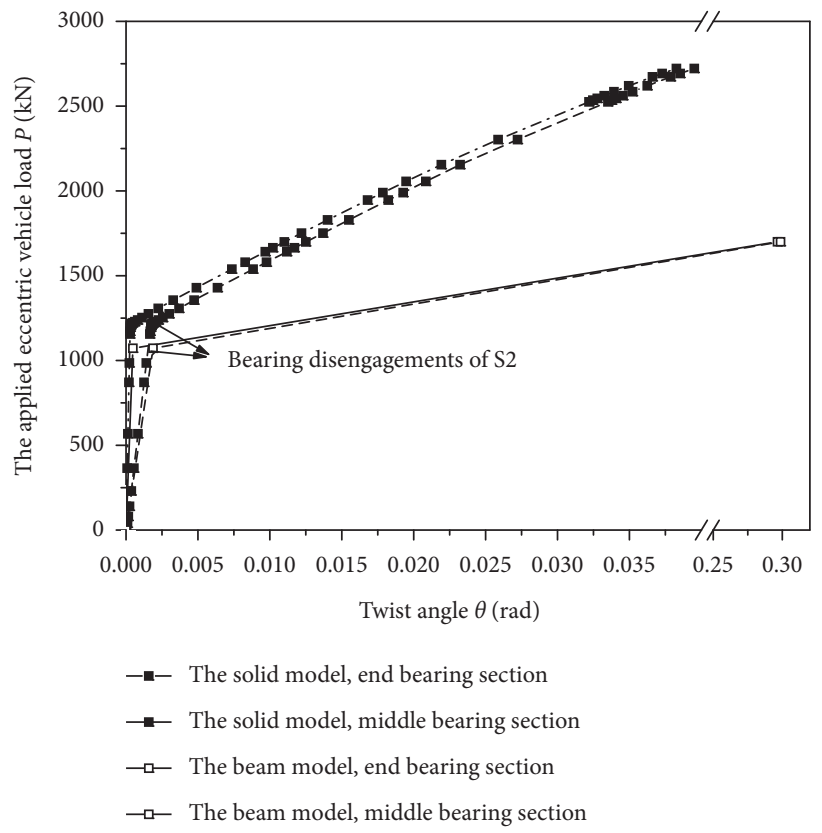

FIgURE 11: Applied load-twist angle relationships calculated from the beam and solid models.

sectional centroid axis to a broken line through the supporting points of all effective bearings. The analysis bridge basically exhibited a rigid-body rotation against the broken line near the ultimate overturning failure.

3.3.4. Bearing Stress. The stress-strain curves of the edges of the rubber pad in the bearings S1 and S3, and the contact conditions of the surfaces between the rubber pads and intermediate steel plates are shown in Figure 12. The stresses at the noneccentric loaded side edges of the rubber pads in S1 and S3 dropped to zero at ultimate failure, indicating that the bearings S1 and S3 had been locally disengaged. Based on the total pressure on the rubber pads, the calculated average compressive stress in the rubber pads of S1 and S3 were 25.8 and $10.1 \mathrm{MPa}$, respectively. However, the compressive stresses in the eccentric loaded edges, which reached approximately 35 and $65 \mathrm{MPa}$ for S1 and S3, respectively, had exceeded the allowable design stress [25] and thus would cause local damage of rubber pads. In addition, the rubber pad in the pot bearings exhibited a basically linear mechanical behavior under the uniform distributed compression (Figure 8), while it showed an obvious nonlinear stressstrain relationship under eccentric compression, as shown in Figure 12. The performance of the middle bearing S3 was important, which provided additional evidence to determine the rotation mechanism of the girder. It could be seen from Figure 12(b) that the middle bearing S3 was far from being 

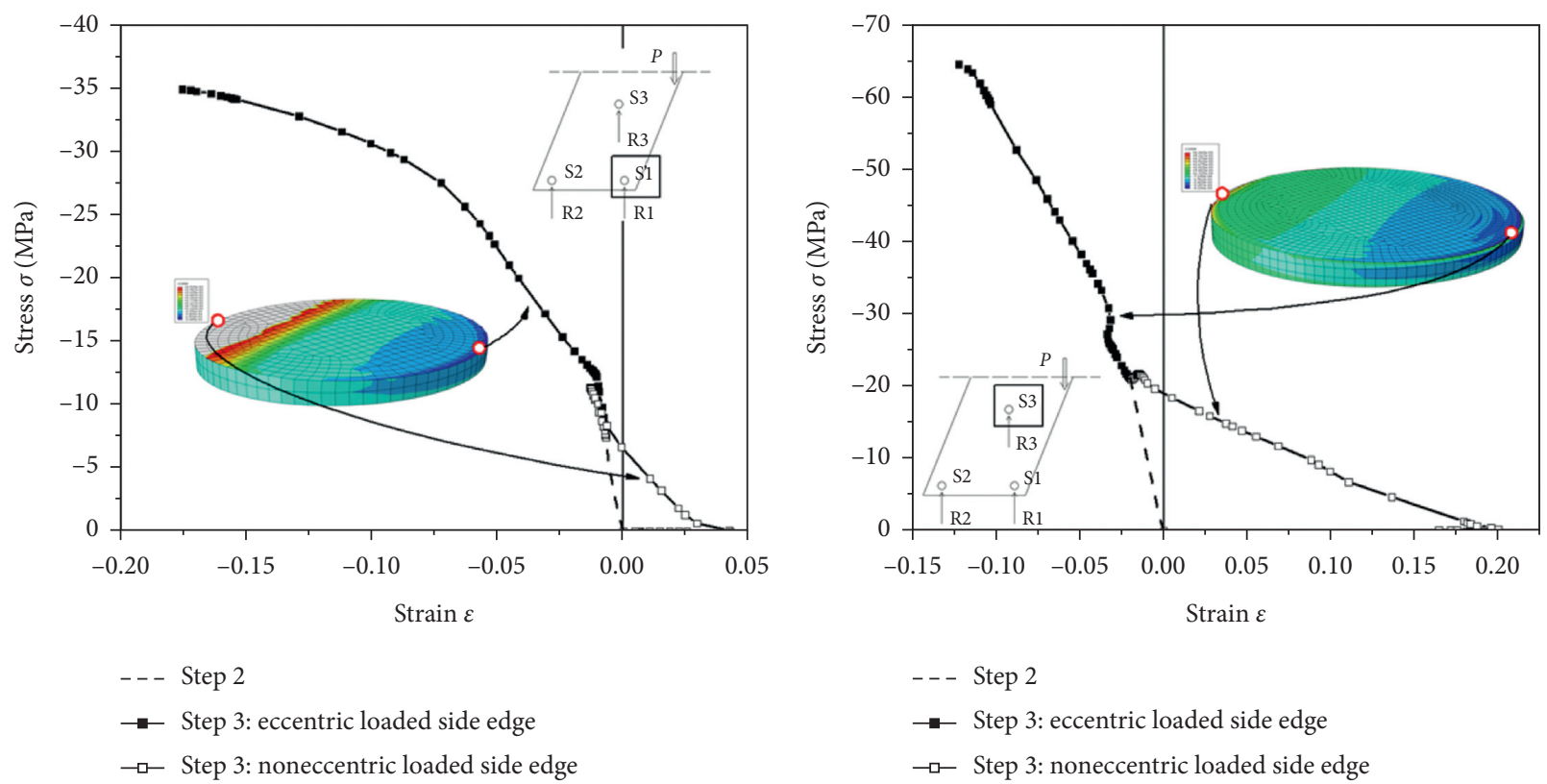

(a)

(b)

FIGURE 12: Stress-strain curves of the edge of the rubber pads calculated from the solid model. (a) End bearing on the eccentric loaded side S1. (b) Middle bearing S3.

totally disengaged, which once again proved the overturning analysis methods based on the rigid-body mechanism (MTPRC 2012) was inaccurate.

\section{Discussion}

4.1. Influence of Transverse Constraints on Overturning Failures. The constraints in the transverse direction in bridges are typically provided by transverse stoppers beside pot bearings or on bent caps, which may become ineffective due to bearing disengagements or excessive transverse reactions. To evaluate the effects of transverse constraints on overturning failures, the types of the end bearings S1 and S2 were interchanged based on the previous solid model (short as original model and thereafter). In the new solid model with bearing types interchanged (short as reference model and thereafter), the transverse stoppers were transformed from S1 to S2, as shown in Figure 13.

The vertical and transverse reactions at critical states (the first bearing disengagement and ultimate failure) calculated from the beam model, original model, and reference model are listed in Table 3 . The states of the end bearings at ultimate failure from the original and reference models are shown in Figure 14. As shown in Table 3, the transverse reactions $\left(R_{\mathrm{T}}\right)$ from the beam model were different from those from the original model, for the reason that the beam model, in which the girder was perfectly supported by point supports rather than the actual surface bearings, would not be able to accurately reflect the bearing surface inclining with the rotation of the girder. Besides, the transverse reactions were also influenced by the reference location in the beam model. As shown in Table 3 and
Figure 14, because of the ineffectiveness of the transverse constraint at S2 due to its disengagement in the reference model, the end bearing section had a relatively larger transverse displacement $(7.2 \mathrm{~cm})$ than that in the original model $(0.5 \mathrm{~cm})$ and accordingly the centroid of the end bearing section in the reference model was transversely closer to the sectional rotation center (S1) compared with the original model. This significantly accelerated the overturning process after the bearing disengagement and also lowered the ultimate overturning failure load $\left(P_{u}\right)$.

The variations in twist angles at the bearing sections from the original and reference models are shown in Figure 15. The twist angles from the reference model increase sharply due to the ineffectiveness of transverse constraint after the disengagement of S2. Overturning ductility parameter $\beta$ was defined as the ratio of $P_{u}$ to the first bearing disengagement load $\left(P_{a}\right)$. As shown in Table 3 , the $\beta$ were 2.23 and 1.10 for the original and reference models, respectively. This finding means if bearing disengagements can be regarded as an "early warning" for overturning failures, the ineffectiveness of transverse constraint makes bridges very brittle that the first bearing disengagements and overturning failures may happen almost simultaneously. However, the ineffectiveness of transverse constraint due to bearing disengagements is hardly considered in engineering design using the beam models. On the other hand, the failure type of transverse stoppers is brittle failure, as the transverse stoppers typically fail in shear. As a result, the strength of transverse stoppers, no matter beside pot bearings or on bent caps, must be checked according to actual transverse reactions in anti-overturning design. 


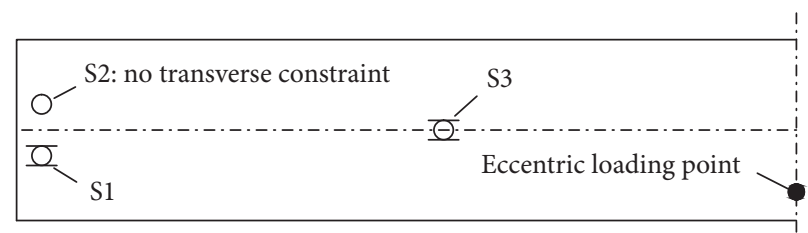

(a)

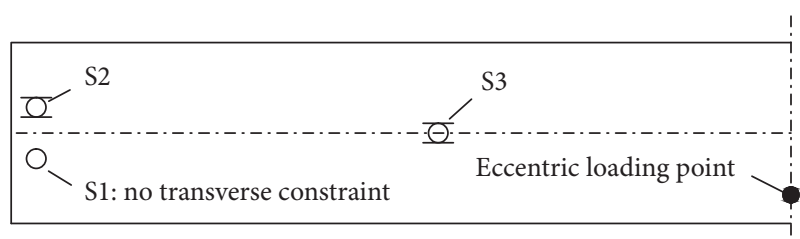

(b)

Figure 13: Different positions of the transverse constraint of the end bearings in the models. (a) The original model. (b) The reference model.

TAвLE 3: Reactions at critical states calculated from the models with different transverse constraints (unit: $\mathrm{kN}$ ).

\begin{tabular}{|c|c|c|c|c|c|c|c|c|c|c|c|}
\hline \multirow{3}{*}{ Model } & \multicolumn{5}{|c|}{ First bearing disengagement } & \multicolumn{6}{|c|}{ Ultimate failure } \\
\hline & \multirow{2}{*}{$P_{a}$} & \multicolumn{2}{|c|}{$R$} & \multicolumn{2}{|c|}{$R_{\mathrm{T}}$} & \multirow{2}{*}{$P_{u}$} & \multirow{2}{*}{$\beta=P_{u} / P_{a}$} & \multicolumn{2}{|c|}{$R$} & \multicolumn{2}{|c|}{$R_{\mathrm{T}}$} \\
\hline & & S1 & S3 & S1 & S3 & & & S1 & S3 & S1 & S3 \\
\hline The beam model & 1074 & 1271 & 8815 & -61 & 61 & - & - & - & - & - & - \\
\hline The original model & 1218 & 1276 & 8950 & -138 & 138 & 2722 & 2.23 & 1028 & 9950 & -1470 & 1470 \\
\hline The reference model & 1112 & 1303 & 8870 & -38 & 38 & 1224 & 1.10 & 1353 & 8876 & 1.5 & -1.5 \\
\hline
\end{tabular}

Note: The positive vertical reactions $(R)$ were in the upward direction; The positive transverse reactions $\left(R_{\mathrm{T}}\right)$ were in the direction from noneccentric loaded side to eccentric loaded side; - indicates the values were not listed because the reactions from the beam model had no sense as discussed above.

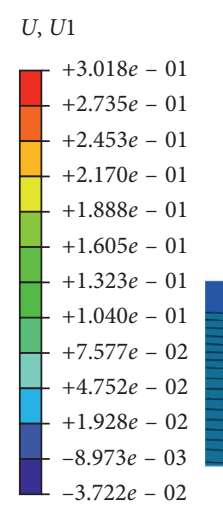

$U, U 1$

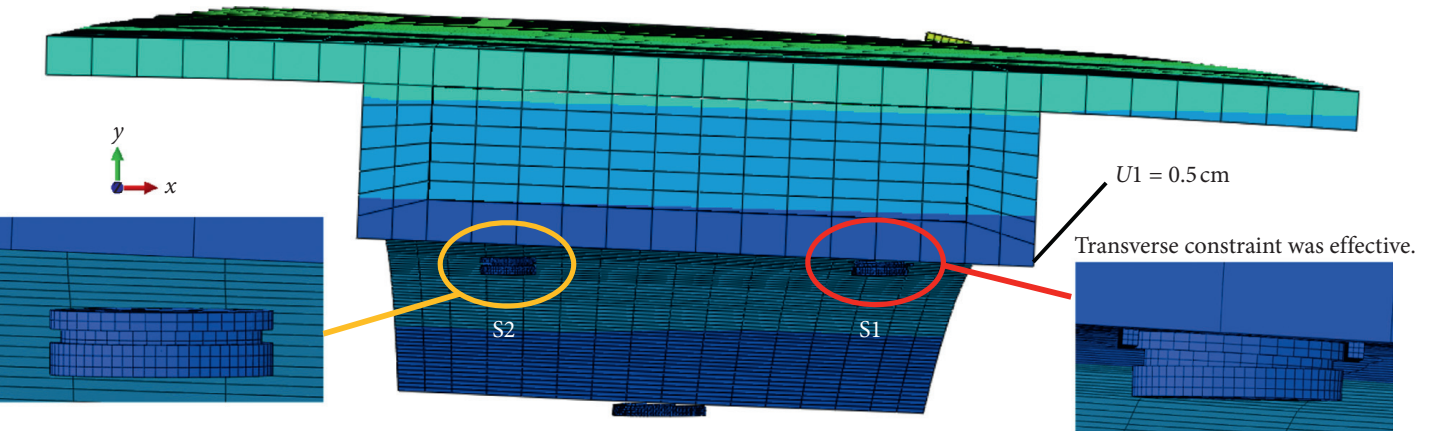

(a)

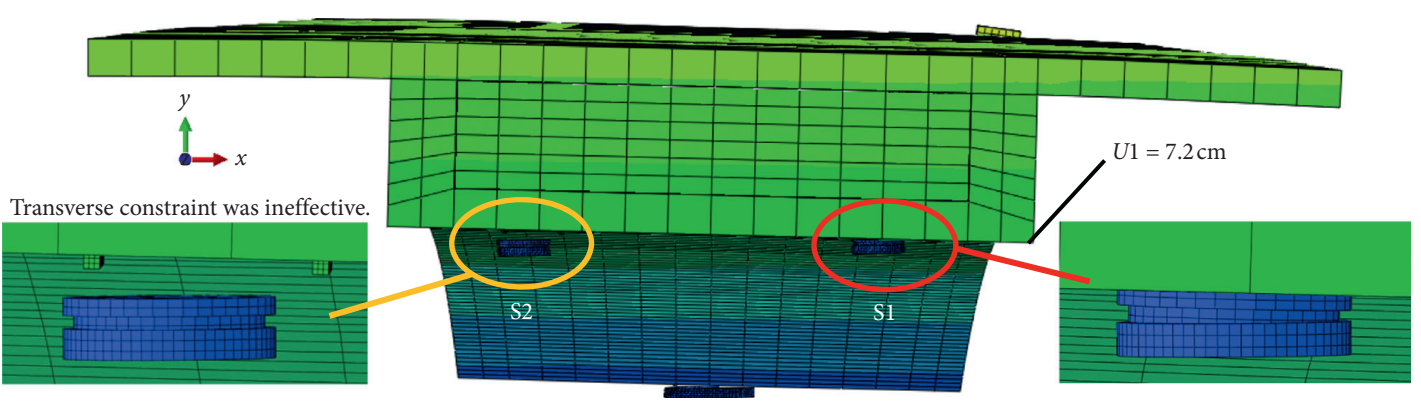

(b)

FIGURE 14: The state of the end bearings in the models at ultimate failure. (a) The original model. (b) The reference model.

4.2. Tensile Anchor for Anti-Overturning Stability. To improve the anti-overturning stability of bridges and avoid brittle overturning failures, tensile anchors were installed at the end bearing sections in the previous solid model as shown in Figure 16, and the results calculated from two new solid models with tensile anchors using different axial stiffness $\left(K_{\mathrm{TA}}\right)$ are compared with those from the previous model without tensile anchors, as shown in Figures 17 and 18. The tensile anchors used steel strands (each strand with a nominal diameter of $15.2 \mathrm{~mm}$, a nominal section area of 


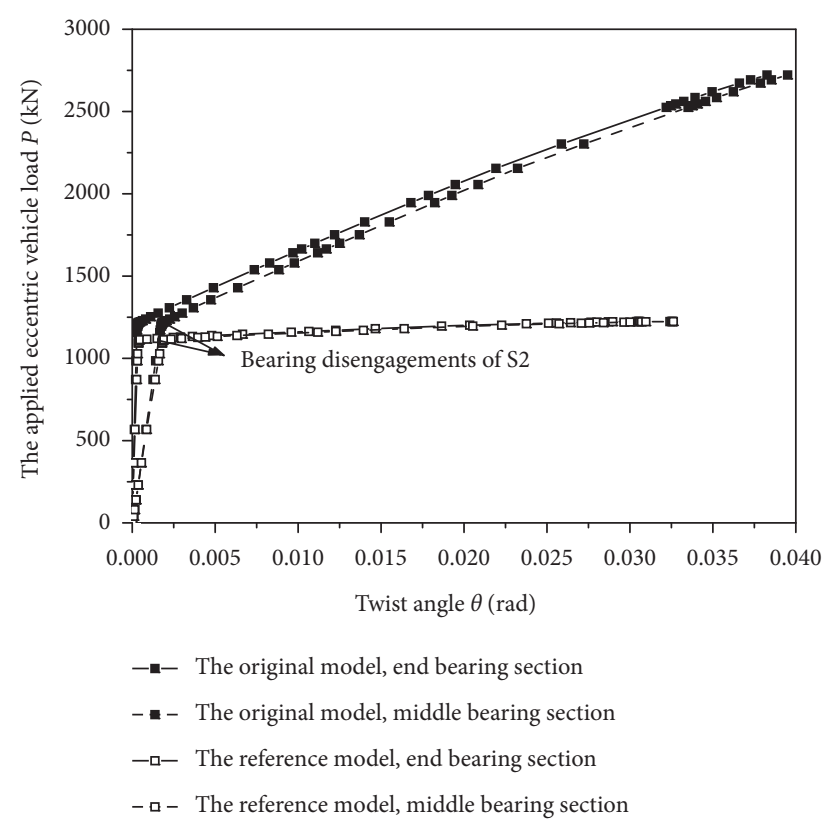

Figure 15: Applied load-twist angle relationships calculated from the original and reference models.

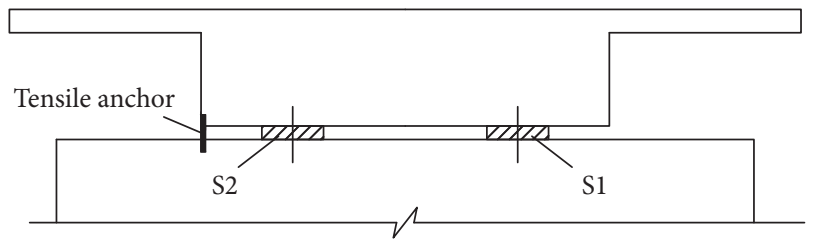

FIgURE 16: Tensile anchor installed at the end bearing sections.

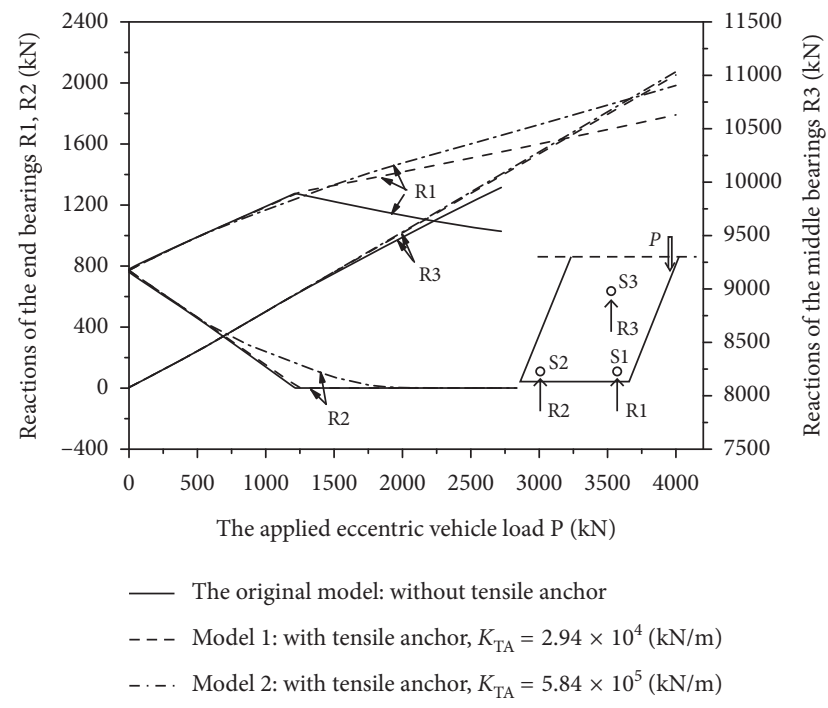

FIgURe 17: Applied load-vertical reactions' relationships calculated from the models with and without tensile anchors.

$140 \mathrm{~mm}^{2}$, and a nominal ultimate strength of $1860 \mathrm{MPa}$ ). The $K_{\mathrm{TA}}$ in two new models were set as $2.94 \times 10^{4} \mathrm{kN} / \mathrm{m}$ (Model 1) and $5.88 \times 10^{5} \mathrm{kN} / \mathrm{m}$ (Model 2), corresponding to one strand and twenty strands, respectively.

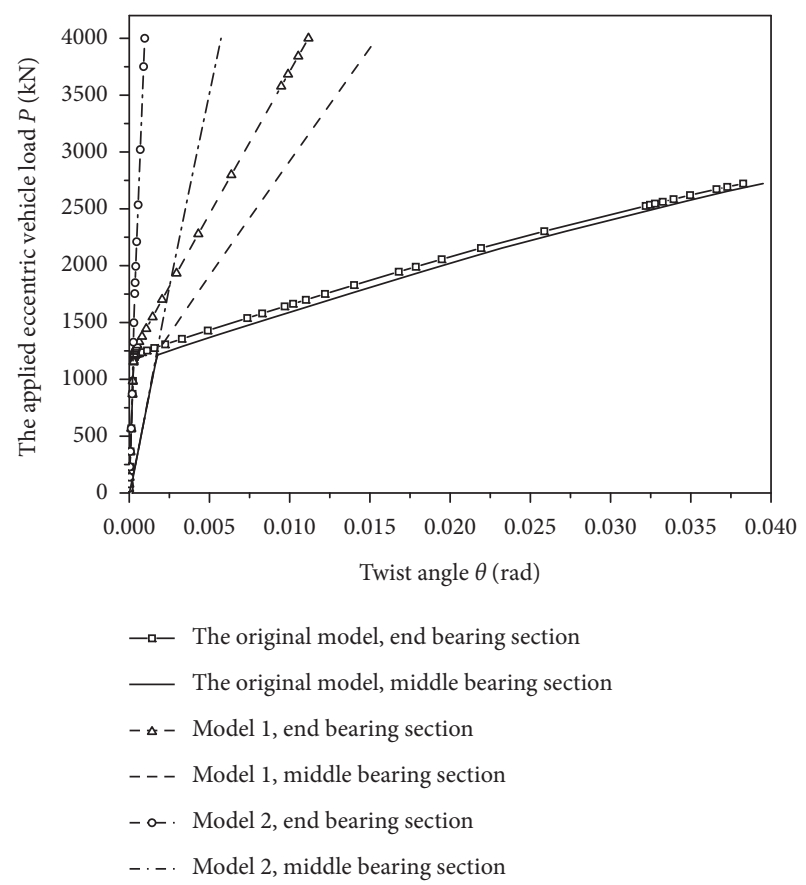

Figure 18: Applied load-twist angle relationships calculated from the models with and without tensile anchors.

Figure 17 shows the variations in the vertical reactions from the three models. The first bearing disengagement appeared at S2 at loads of $1215 \mathrm{kN}, 1267 \mathrm{kN}$, and $2535 \mathrm{kN}$ for the original model, Model 1, and Model 2, respectively, indicating the tensile anchors with sufficient stiffness could delay the first bearing disengagement. After the bearing disengagements, the reactions $\mathrm{R} 2$ and $\mathrm{R} 3$ in the three models were similar, while the reactions R1 in the two models with tensile anchors were significantly different from that in the original model. This is because although S2 disengaged, the torsion resistance system (deformable-body rotation mechanism) was not changed due to the tensile reactions provided by the anchors installed on the side of S2. The variations in the twist angles from the three models are shown in Figure 18. The twist angles in Model 1 and Model 2 were apparently smaller compared with the original model. Furthermore, Model 2 in which the tensile anchors using a sufficient stiffness had an almost linear elastic mechanical behavior even after the bearing disengagements. As such, the brittle overturning failures turn out to be ductile strength failures, depending on the tensile strength of tensile anchors and compressive strength of rubber bearings; besides, overturning analysis becomes linear elastic analysis, which can be easily conducted using general beam models.

\section{Summary and Conclusions}

Regarding the overturning failures in continuous girder bridges, full-range nonlinear numerical analysis of typical single-support bridges was conducted in this study. The results of the numerical analysis provided quantitative data on and fundamental insight into the failure mechanics of overturning failures. On the basis of the analysis results and discussions, the following conclusions can be drawn: 
(1) Overturning failures start with bearing disengagements. After the first bearing disengagement, the torsion resistance system of a girder significantly changes while the bending resistance system of the girder does not. From the first bearing disengagement to overturning failure, the rotation mechanism gradually transits from deformable-body rotation to rigid-body rotation. The girder exhibits an almost rigid-body rotation against the broken line through effective bearings at ultimate failure. This finding indicates that the current code method, which is based on deformable-body rotation mechanism, is on the conservative side.

(2) The rubber in pot bearings has a large elastic module and high compressive strength because of the triaxial constraint state. The local stress at the edge of rubber pads may exceed the allowable value although the averaged pressure on rubber pads is relatively small. This may result in local damage in rubber bearings.

(3) The transverse constraint has an important effect on anti-overturning stability. The ineffectiveness of transverse constraint will significantly reduce the ultimate overturning failure load and make overturning failures much more brittle. As a result, transverse constraint at each bearing section must be carefully designed and checked for its strength according to actual transverse reactions.

(4) Tensile anchors are a convenient and efficient method to improve anti-overturning stability and avoid brittle overturning failures. Bridges using tensile anchors with sufficient stiffness can be simply analyzed by a linear elastic beam model. The axial stiffness of tensile anchors is suggested to be in the same order of magnitude as the axial stiffness of adjacent bearings.

Based on the comparisons of analysis results from the solid and beam models, some suggestions are provided for the anti-overturning design method using the beam models in practice as follows:

(1) Overturning failures never happen before bearing disengagements. The beam models yield accurate predictions of vertical reactions and torsional deformations until the first bearing disengagements. The axial stiffness of each bearing can be set as a unified value and keeps constant in practice.

(2) The beam models (whether using compression-only bearings or not) fail to give accurate predictions after bearing disengagements because beam models are unable to realize the transition of the rotation mechanism from deformable-body rotation to rigidbody rotation due to the bearing disengagement.

(3) Torsional deformations and transverse reactions of the girder after bearing disengagements and maximum stresses in bearings must be calculated using solid models, including boundary and geometric nonlinearities, taking into consideration the actual interaction between girder and bearings.
(4) Reliable transverse stoppers and tensile anchors at bearing sections are strongly recommended in practical design for a significant improvement on anti-overturning stability and ductility.

\section{Data Availability}

The research data used to support the findings of this study are available from the corresponding author upon request.

\section{Conflicts of Interest}

The authors declare that they have no conflicts of interest.

\section{Acknowledgments}

This study was sponsored by the National Natural Science Foundation of China (Grant No. 52008303), China Postdoctoral Science Foundation (Grant No. 2020M671237), and Tongji Architectural Design (Group) Co. Ltd. (Grant No. 2020KY07).

\section{References}

[1] MTPRC (Ministry of Transport of the People's Republic of China), Specifications for Design of Highway Reinforced Concrete and Prestressed Concrete Bridges and Culverts, JTG 3362-2018, China Communications Press, Beijing, China, 2018, in Chinese.

[2] Shanghai Municipal Road Transport Administrative Bureau, Report on the Study of Overturning Checking Standards of Girder Bridges in Shanghai, Tongji University, Shanghai, China, 2017, in Chinese.

[3] D. Zhuang, "Study of overturning stability issues of box girder bridges under action of eccentric load," Bridge Construction, vol. 44, no. 2, pp. 27-31, 2014, in Chinese.

[4] Z. Fang, "Study of overturning issues of single supported girder bridges," Bridges, vol. 22013, in Chinese.

[5] MTPRC (Ministry of Transport of the People's Republic of China), Specifications for Design of Highway Reinforced Concrete and Prestressed Concrete Bridges and Culverts (Draft for Comments), JTG D62-2012, China Communications Press, Beijing, China, 2012, in Chinese.

[6] MTPRC (Ministry of Transport of the People's Republic of China), Code for Design of Highway Reinforced Concrete and Prestressed Concrete Bridges and Culverts, JTG D62-2004, China Communications Press, Beijing, China, 2004, in Chinese.

[7] X. Li, Y. Lu, and L. Zhou, "Research on overturning mechanism \& reinforcement technology of continuous beam bridge with single column pier," China Municipal Engineering, vol. 4, pp. 18-20, 2016, in Chinese.

[8] W. Peng, R. Pan, Majun et al., "Study of overturning failure modes and anti-overturning calculation methods for singlecolumn pier beam bridges," Bridge Construction, vol. 46, no. 02, pp. 28-33, 2016, in Chinese.

[9] W. Xiong, S. Lu, X. Gong et al., "Critical condition analysis of overturned bridges with single-column-piers and applicability of design standards," China Journal of Highway and Transport, vol. 031, no. 003, pp. 49-58, 2018, in Chinese.

[10] W. Xiong, C. S. Cai, B. Kong et al., "Overturning-collapse modeling and safety assessment for bridges supported by 
single-column piers," Journal of Bridge Engineering, vol. 22, no. 11, Article ID 04017084, 2017.

[11] Y. Chen, G. Xin, Y. Li et al., "Anti-overturning stability study of a continuous steel-concrete composite girder bridge with single column piers," in Proceedings of the Asia Pacific Transportation Development Conference, pp. 571-579, Beijing, China, May 2014.

[12] W. Peng, J. Shen, X. Tang et al., "Review, analysis, and insights on recent typical bridge accidents," China Journal of Highway and Transport, vol. 32, no. 12, pp. 132-144, 2019, in Chinese.

[13] W. Peng, Z. Zhu, G. Chen et al., "Research on overturning failure mode of beam bridges and applicability of calculation method," China Civil Engineering Journal, vol. 52, no. 12, pp. 104-113, 2019, in Chinese.

[14] G. Li, "Analysis of bridge anti-overturning design based on new version of "Specifications for design of highway reinforced concrete and prestressed concrete bridges and culverts"' Journal of Bohai University (Natural Science Edition), vol. 40, no. 3, pp. 263-268, 2019, in Chinese.

[15] W. B. Peng, F. Dai, and E. Taciroglu, "Research on mechanism of overturning failure for single-column pier bridge," in Proceedings of the 2014 International Conference on Computing in Civil and Building Engineering, Orlando, FL, USA, June 2014.

[16] W. B. Peng, H. Zhao, F. Dai et al., "Analytical method for overturning limit analysis of single-column pier bridges," Journal of Performance of Constructed Facilities, vol. 31, no. 4, Article ID 04017007, 2017.

[17] D. H. Dan, X. W. Yu, X. F. Yan et al., "Monitoring and evaluation of overturning resistance of box girder bridges based on time-varying reliability analysis," Journal of Performance of Constructed Facilities, vol. 34, no. 1, Article ID 04019101, 2020.

[18] D. Zhuang, R. Xiao, L. Jia, and B. Sun, "Failure analysis for overall stability against sliding and overturning of a girder bridge," Engineering Failure Analysis, vol. 109, Article ID 104271, 2020.

[19] X. F. Shi, Z. J. Zhou, and X. Ruan, "Failure analysis of a girder bridge collapse under eccentric heavy vehicles," Journal of Bridge Engineering, vol. 21, no. 12, Article ID 05016009, 2016.

[20] X. Shi, Z. Cao, H. Ma et al., "Failure analysis on a curved girder bridge collapse under eccentric heavy vehicles using explicit finite element method: case study," Journal of Bridge Engineering, vol. 23, no. 3, pp. 1-11, 2018.

[21] F. Liu, S. Liu, H. Zhang et al., "Research on overturning resistance of single-column curved rigid frame ramp bridge," Journal of Lanzhou Jiaotong University, vol. 04, pp. 32-36, 2012, in Chinese.

[22] K. Lee, J. B. Andrawes, and Y. H. KangKim, "A study on overturning failure of horizontally curved single steel box girders," Engineering Failure Analysis, vol. 97, pp. 20-31, 2019.

[23] lichu Fan, Prestressed Concrete Continuous Girder Bridges, China Communications Press, Beijing, China, 1988, in Chinese.

[24] Q. Liu, Analysis of Friction-Slip Characteristics of Pot Bearings in Continuous Curved Girder Bridges, Chang'an University, Xi'an, China, 2019, in Chinese.

[25] China Communications Press, JT/T 391-2009 Pot Bearings for Highway Bridges, China Communications Press, Beijing, China, 2009, in Chinese.

[26] Simulia, Abaqus User's Manual 6.11, Simulia, Providence, RI, USA, 2011. 